Tema: Logística Internacional

\title{
REGIMES ESPECIAIS-REDUÇÃO SIGNIFICATIVA NO CUSTO FINAL DA LOGÍSTICA INTERNACIONAL*
}

Jaqueline Couri Rolim ${ }^{1}$

\section{Resumo}

Os regimes aduaneiros especiais se distinguem do regime comum pela redução, suspensão ou isenção de tributos incidentes nas operações de comércio exterior. Esses regimes podem facilitar as operações de importação, devido à alta carga tributária, incentivando o desenvolvimento de determinadas regiões do país ou de setores específicos da economia, melhorando a competitividade de seus produtos. $O$ Ex-Tarifário, consiste na importação de material sem similaridade nacional, podendo ser peça, equipamento ou linha de produção, com prazo de validade de um ano, podendo ser prorrogado por mais um ano, com redução significativa no imposto de importação para 2\%, gerando uma economia total expressiva, pois os cálculos dos tributos federais são em cascata.

Palavras-chave: Ex-tarifário.

\section{SPECIAL REGIMENS-SIGNIFICANT REDUCTION IN THE END COST OF INTERNATIONAL LOGISTICS}

\begin{abstract}
Special regimens differ from the standard ones due to reduction, suspension or exemption of taxes in foreign trade operations. Due to excessive tax burden, these regimens play a very important role in assisting importers logistics operations by stimulating the development in given regions of the country or specific areas of the economy, thus increasing product competitiveness. The Ex-Tarifário consists in importing materials without similarity in the domestic market. Material imported can range from a single part to a complex high value machinery or even a whole production line for a period of one year, extendable for another one, with an expressive reduction on import duty, which can be as low as $2 \%$, thus generating meaninful savings, considering the ripple effect of federal taxes.
\end{abstract}

Keywords: Ex-tarifário.

1 Admistração de Empresas com Ênfase em Comércio Exterior, Bacharel, Gerente, Desembaraço Aduaneiro, Interfreight Logistics, Rio de Janeiro, RJ e Brasil.

\footnotetext{
* Contribuição técnica ao 33० Seminário de Logística - Suprimentos, PCP, Transportes, 13 a 16 de maio de 2014, São Paulo, SP, Brasil.
} 


\section{INTRODUÇÃO}

A logística internacional, ao longo dos tempos, mesmo com o desenvolvimento tecnológico proeminente, vem sofrendo com a falta de infraestrutura portuária, ferroviária e aeroviária, devido ao alto volume de cargas movimentadas [1].

O Brasil, apesar de participar de acordos bilaterais com diversos países, o que em tese, facilitaria o comércio internacional, esbarra no problema da alta tributação e na falta de investimento na indústria nacional, pois diversos itens necessários a expansão dos terminais, zonas primárias e secundárias, não são produzidos no país, tendo somente como alternativa a importação.

O Ex-tarifário, principalmente para a Siderurgia, é uma alternativa viável, pois além de reduzir significativamente a tributação, tem validade de até 2 anos, ou seja, se a empresa importar regularmente uma peça ou equipamento, durante o período de vigência, haverá a redução de alíquota do imposto de importação, o que reduzirá também, de maneira significativa, o custo final do material.

\section{MATERIAIS E MÉTODOS}

$\checkmark$ No site do MDIC (Ministério de Desenvolvimento, Indústria e Comércio), consta o detalhamento para pleitear este regime especial;

$\checkmark$ As planilhas elaboradas estão de acordo com a legislação vigente da RFB (Receita Federal do Brasil);

$\checkmark$ O exemplo de classificação fiscal (NCM) foi extraído do site da Aduaneiras.

\section{RESULTADOS E DISCUSSÃO}

Tabela 1. TEC (Tarifa Externa Comum) [3]

\begin{tabular}{|c|c|c|c|c|c|c|c|c|}
\hline \multirow{2}{*}{$\begin{array}{l}\text { Item: } \\
\text { Código } \\
\text { NCM }\end{array}$} & \multirow{2}{*}{\begin{tabular}{|l|}
8471.90 .90 \\
Descrição
\end{tabular}} & \multirow[t]{2}{*}{ Unida } & \multicolumn{6}{|c|}{ Unidade: Unidade } \\
\hline & & & $\begin{array}{c}\text { II } \\
\text { Normal }\end{array}$ & $\begin{array}{c}\text { II } \\
\text { Vigente }\end{array}$ & IPI & $\begin{array}{c}\text { Pis / } \\
\text { Pasep }\end{array}$ & Cofins & ICMS \\
\hline 8471.90 .90 & Outros & & 16 & & 15 & 1,65 & 8,6 & TN \\
\hline 8471.90 .90 & $\begin{array}{l}\text { Ex } 001 \text { - Banc } \\
\text { comando eletr } \\
\text { ABS e ESP) e } \\
\text { programação } \\
\text { programação, } \\
\text { diferente ao m } \\
\text { de parâmetros } \\
\text { comando eletr }\end{array}$ & $\begin{array}{l}\text { as automáticas para programação de unidades de } \\
\text { ico (ECU) de sistema de freios automotivos (Módulos } \\
\text { arquivos de extensão PCC, com tempo de } \\
50 \text { a } 120 \text { segundos, com nichos independentes de } \\
\text { da um podendo programar uma ECU com um software } \\
\text { mo tempo, dotada de unidade de scanner para leitura } \\
\text { nidade de gravação e avaliação de software, painel de } \\
\text { ico }\end{array}$ & 16 & 2 & 15 & 1,65 & 8,6 & $\mathrm{TN}$ \\
\hline 8471.90 .90 & $\begin{array}{l}\text { Ex } 002 \text { - Máq } \\
\text { imobilizadora } \\
\text { chaves, grav } \\
\text { gerenciamen }\end{array}$ & $\begin{array}{l}\text { as automáticas para programar chaves } \\
\text { automotivas, com funções de programação de } \\
\text { io do código PIN, gravação de falhas e } \\
\text { de dados }\end{array}$ & 16 & 2 & 15 & 1,65 & 8,6 & TN \\
\hline 8471.90 .90 & $\begin{array}{l}\text { Ex } 003 \text { - Banc } \\
\text { comando eletr } \\
\text { ABS e ESP) e } \\
\text { programação } \\
\text { datamatrix, co } \\
\text { e avaliação de } \\
\text { eletrônico }\end{array}$ & $\begin{array}{l}\text { as automáticas para programação de unidades de } \\
\text { ico (ECU) de sistema de freios automotivos (módulos } \\
\text { arquivos de extensão, PCC, com tempo de } \\
50 \text { a } 120 \text { segundos, dotadas de "scanner" de } \\
\text { ctor elétrico para leitura da ECU, unidade de gravação } \\
\text { oftware, painel de controle elétrico e painel de comando }\end{array}$ & 16 & 2 & 15 & 1,65 & 8,6 & TN \\
\hline 8471.90 .90 & $\begin{array}{l}\text { Ex } 004 \text { - Banc } \\
\text { eletrônico com } \\
\text { do protocolo d } \\
\text { circuit), com te } \\
\text { frequência de } \\
\text { computador, ir } \\
\text { elétrico. }\end{array}$ & $\begin{array}{l}\text { as para programação do sensor do corpo de borboleta } \\
\text { ados de posição, linearidade e sincronismo, por meio } \\
\text { omunicação Asic (Application - specific integrated } \\
\text { oo de programação de 10s/peças, potência de } 5 \mathrm{kVA} \text { e } \\
\text { Hz, dotadas de: unidade de comando central com } \\
\text { rface de comunicação, fontes de alimentação e painel }\end{array}$ & 16 & 2 & 15 & 1,65 & 8,6 & TN \\
\hline
\end{tabular}

* Contribuição técnica ao $33^{\circ}$ Seminário de Logística - Suprimentos, PCP, Transportes, 13 a 16 de maio de 2014, São Paulo, SP, Brasil. 
Tabela 2. Tributação Normal [2]

\begin{tabular}{|c|c|c|}
\hline \multicolumn{3}{|c|}{ PLANI LHA DE CÁLCULOS } \\
\hline \multicolumn{3}{|c|}{ IMPORTAÇÃO MARÍTIMA } \\
\hline \multicolumn{3}{|c|}{ SÃO PAULO } \\
\hline Valor Aduaneiro & $\mathbf{R} \$$ & $15.000 .000,00$ \\
\hline Alíquota do I.I. & & 16,00 \\
\hline Alíquota do I.P.I. & & 5,00 \\
\hline Alíquota do Pis/Pasep & & 1,65 \\
\hline Alíquota do Cofins & & 7,60 \\
\hline Alíquota do ICMS & & 18,00 \\
\hline Imposto de Importação & R\$ & $2.400 .000,00$ \\
\hline I.P.I. & $\mathbf{R} \$$ & $870.000,00$ \\
\hline Pis na importação & $\mathbf{R} \$$ & $247.500,00$ \\
\hline Cofins na Importação & $\mathbf{R} \$$ & $1.140 .000,00$ \\
\hline Taxa do Siscomex & $\mathbf{R} \$$ & 214,50 \\
\hline Despesas Aduaneiras & $\mathbf{R} \mathbf{S}$ & - \\
\hline Base de cálculo do ICMS & $\mathbf{R} \$$ & $23.972 .822,56$ \\
\hline Total ICMS (18\%) & $\mathbf{R} \$$ & $4.315 .108,06$ \\
\hline
\end{tabular}

Tabela 3. Ex-tarifário [2]

\begin{tabular}{|c|c|c|}
\hline \multicolumn{3}{|c|}{ PLANI LHA DE CÁLCULOS } \\
\hline \multicolumn{3}{|c|}{ IMPORTAÇÃO MARÍTIMA } \\
\hline \multicolumn{3}{|c|}{ S̃̃O PAULO } \\
\hline Valor Aduaneiro & $\mathbf{R} \$$ & $15.000 .000,00$ \\
\hline Alíquota do I.I. & & 2,00 \\
\hline Alíquota do I.P.I. & & 5,00 \\
\hline Alíquota do Pis/Pasep & & 1,65 \\
\hline Alíquota do Cofins & & 7,60 \\
\hline Alíquota do ICMS & & 18,00 \\
\hline Imposto de Importação & $\mathbf{R} \$$ & $300.000,00$ \\
\hline I.P.I. & $\mathbf{R} \$$ & $765.000,00$ \\
\hline Pis na importação & $\mathbf{R} \$$ & $247.500,00$ \\
\hline Cofins na Importação & $\mathbf{R} \$$ & $1.140 .000,00$ \\
\hline Taxa do Siscomex & $\mathbf{R} \$$ & 214,50 \\
\hline Despesas Aduaneiras & $\underline{\mathbf{R}}$ & - \\
\hline Base de cálculo do ICMS & $\mathbf{R} \$$ & 21.283.798,17 \\
\hline Total ICMS (18\%) & $\mathbf{R} \$$ & $3.831 .083,67$ \\
\hline
\end{tabular}

Obs.: As despesas aduaneiras não foram incluídas na base de cálculo, pois as mesmas somente poderão ser obtidas, através de uma importação efetiva.

* Contribuição técnica ao $33^{\circ}$ Seminário de Logística - Suprimentos, PCP, Transportes, 13 a 16 de maio de 2014, São Paulo, SP, Brasil. 
Após pesquisa detalhada do assunto, é unanime a opinião que a redução dos tributos obtidos no Ex-tarifário, tem incentivado as empresas a incrementar e/ou ampliar suas linhas de produção,

\section{CONCLUSÃo}

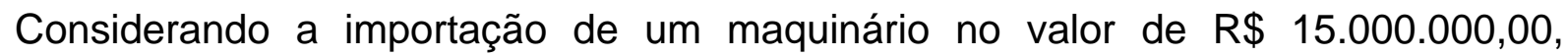
obteve-se uma redução de $R$ \$ 2.205.000,00 de tributos federais e $R \$ 484.024,39$ de ICMS.

Serão apresentados no $33^{\circ}$ Seminário da ABM, slides ilustrativos de um processo de importação.

\section{Agradecimentos}

Agradeço a Sra. Claudia Creste pela revisão do texto em português, o Sr. Gerson Assis pela redação em inglês, a Sra. Gitânia Lira e Lucas Nogueira pela revisão final, a Diretoria da Interfreight pela confiança depositada ao longo destes 12 anos e toda a minha Equipe.

\section{REFERÊNCIAS}

1 Caex - Comitê de Análise de ex-tarifários. Resolução CAMEX 17. MDIC, Ministério do Desenvolvimento, Indústria e Comércio. 24 abr. 2012 [citado em 27 fev. 2014]. Disponível em: http://www.desenvolvimento.gov.br/arquivos/dwnl_1334182975.pdf.

2 RFB - Receita Federal do Brasil. LEI no 12.865. Receita Federal do Brasil. 9 out. 2013 [citado em 27 fev. 2014]. Disponível em: http://www4.receita.fazenda.gov.br/simulador/.

3 TEC - Tarifa Externa Comum. Home - Código NCM. Aduaneiras. 27 fev. 2014 [citado em 27 fev. 2014]. Disponível em: http://tecwinweb.aduaneiras.com.br/Modulos/CodigoNcm/CodigoNcm.aspx?codigoNcm $=84719090$. 